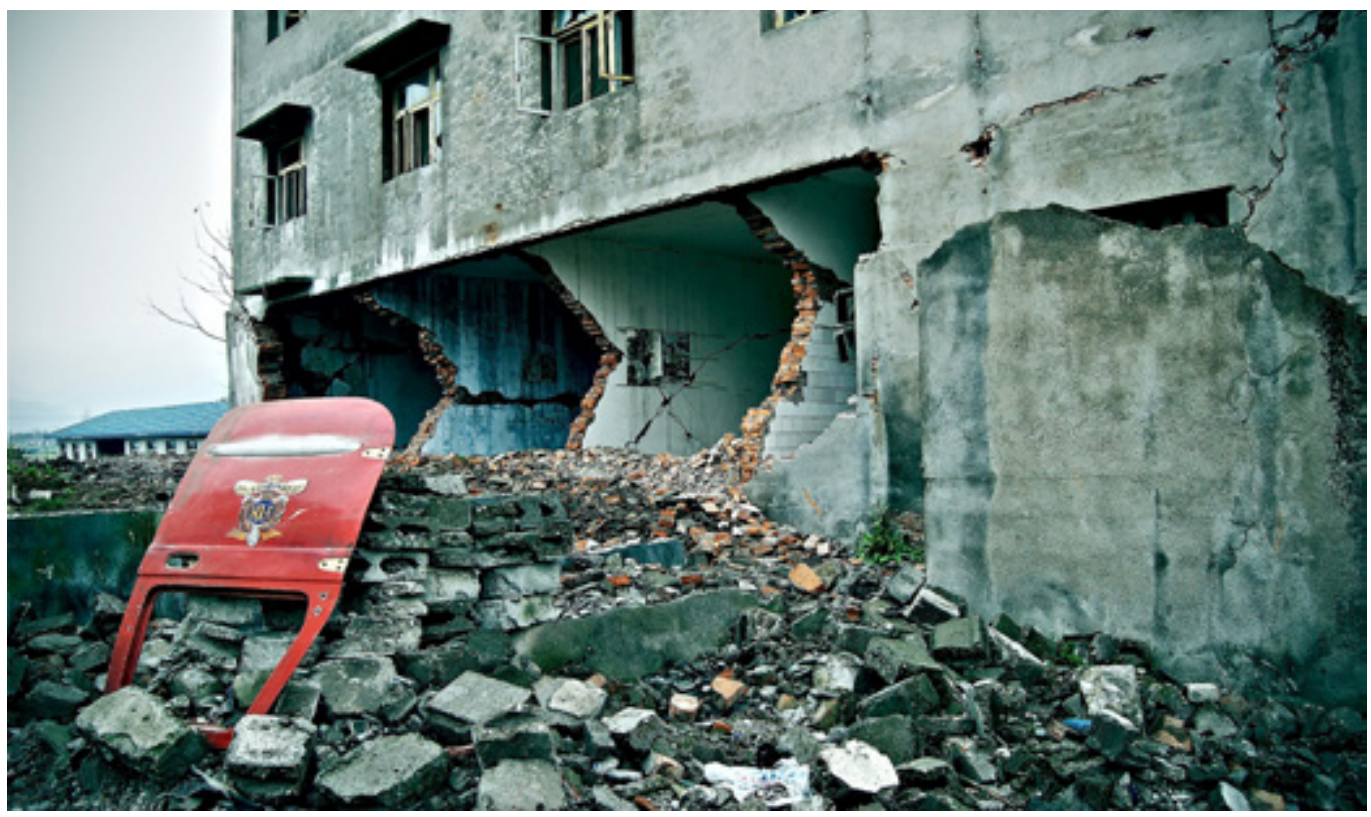

\section{Sichuan, Year Zero?}

Yi Kang

The aftermath of the Sichuan earthquake has witnessed the development of a variety of indigenous NGOs. While the first two years after the earthquake were a 'honeymoon' period for local governments and NGOs, after 2010 feelings became more mixed. On the one hand, a series of policies openly acknowledged the important role of social organisations in supplying public goods and social services; on the other, new laws and regulations not only restricted the activities of overseas NGOs in China, but also severely limited access to foreign funding for domestic organisations.

\section{The ruins of a hospital in rural Sichuan. Photo: Dominiqueb. Flickr.com}

still clearly remember how during my visits to the quake-struck areas one year after the Wenchuan earthquake, local officials would unanimously commend the various social organisations and volunteer groups for their enthusiastic, industrious, and effective relief efforts. Back then, I also witnessed the establishment of a number of indigenous NGOs. In recent years, however, I have found at my field sites that local government support towards social organisations has floundered. I have also heard more and more complaints from NGO representatives about the difficulty of working with local officials. As the tenth anniversary of the Wechuan earthquake approaches, the time is ripe to look back and ask whether the earthquake really was a major turning point for Chinese society, as it was presented at that time (Shieh and Deng 2011; 
Teets 2009). Conversely, looking forward, is it still possible to say that a vibrant civil society is on the rise in China?

Throughout my field research in the areas affected by the Wenchuan earthquake over the past nine years, I have witnessed the development of a variety of indigenous NGOs-a term in which I also include nonprofit organisations voluntarily organised by citizens, even if they do not have an official registration-which actively assisted in the post-disaster recovery and continued working in local communities after reconstruction was completed. In particular, I looked at their evolving interactions with local governments. The first two years after the earthquake were a 'honeymoon' period for local governments and NGOs. In interviews, both sides frequently highlighted each other's 'collaborative role' in post-disaster rehabilitation. However, after 2010, feelings were more mixed. On the one hand, a series of policies openly acknowledged the legitimate and important role of social organisations in supplying public goods and social services in China, facilitating their registration and encouraging them to seek funding from the government and various domestic foundations in order to provide social services. However, the 2017 Foreign NGO Management Law not only restricted the activities of overseas NGOs in China but also severely limited access to foreign funding for domestic NGOs, threatening their very survival (Franceschini and Nesossi 2017). When I returned to Sichuan in recent years, I found that the divergence in the development trajectories of different types of NGOs was becoming more apparent.

Many NGOs that gained official registration in the earthquake-affected areas between 2009 and 2010 were sponsored, entirely or partially, by local civil affairs bureaus through quasiofficial organs such as social work associations (shehui gongzuo xiehui). From their inception, these NGOs eagerly established alliances with government agencies, and thus state actors had great confidence in their loyalty. Like parents rearing their children, local governments generously offered economic support and policy favours to them. For instance, despite the lack of experience of these NGOs, local government agencies continuously contracted them for various public services and even entrusted them with large-scale policy, pilot policy programmes. In return, these NGOs carefully catered to the government's needs and satisfied the bureaucratic culture of upward reporting, enabling the relevant officials to take the credit. Unsurprisingly, such organisations easily grew and expanded over the years, and even engaged in a limited degree of policy advocacy. Such groups quickly came to dominate, or even monopolise, the local NGO 'ecosystem'. However, depending on continuous state support, sooner or later they began resembling government agencies themselves, which, in the eyes of residents and of certain sober officials, diminished their value as a third party standing between the state and citizens.

After the earthquake, a few survivors and volunteers decided to found NGOs by themselves, without any support from the local state. Such grassroots organisations had neither abundant resources nor close contact with state actors, and thus usually had a hard time fending for themselves in the years after their establishment. To survive, they actively expanded their networks to seek donations and advice. Through these networks, they made friends from different parts of the world and gained exposure to foreign civil society practices and knowledge. Given their limited resources and narrow scope, the government often paid little attention to them, and usually generally regarded them in a positive light. However, as these grassroots organisations steadily grew-securing funding from a wide range of non-governmental sources, building professional expertise, and gaining wider support in the local communitieslocal governments inevitably took notice and attempted to intervene in their development, compelling them to demonstrate loyalty. While striving to keep an optimal distance from the government, these NGOs cautiously avoided 
offending local officials who could have easily threatened their survival. Some eventually drew closer to the government, applying for government-funded projects and seeking opportunities to ingratiate themselves with powerful government authorities.

Overseas NGOs also played a crucial role in post-earthquake relief, rehabilitation, and reconstruction. They swiftly arrived at the quake-struck areas and joined the relief work. Throughout the rehabilitation process, they provided a variety of different kinds of support (e.g., funding, human resources, technical assistance, etc.) to earthquake survivors, local governments, and indigenous social organisations. They were generally well received by residents and local officials. After things became more stable, quite a few overseas NGOs formally established local branches or supported the founding of indigenous NGOs in order to continue participating in community building. New organisations that received generous overseas sponsorship actively launched various public services programmes, which were warmly welcomed by local governments.

Nonetheless, officials tolerated a certain degree of NGO autonomy only as long as they could harness the resources of these organisations for their own benefit and, as time went by, tensions gradually emerged. Local officials not only continuously asked these NGOs to contribute resources and ideas to fulfil governmental agendas, but also increasingly intervened in their operations to ensure that they followed the directives of local authorities. NGO staff members had to spend their time drafting and submitting proposals and reports requested by officials, even if they regarded such activities as being a waste of resources and hence handled them perfunctorily. In turn, feeling dissatisfied, officials intentionally made things difficult for these organisations. In the past few years, the diminishing ability to determine local policies and priorities, as well as the government's bureaucratic style and administrative interventions, has frustrated quite a few overseas NGOs that funded local NGO activities. One after another, they have reduced or withdrawn their financial support. In 2016 and 2017, many analysts were discussing the chilling effects of the Foreign NGO Management Law, but what I had observed in Sichuan in previous years showed that even without explicit legal intervention, local governments would discourage overseas support and funding to local NGOs by simply taking a predatory approach: all they had to do was consume the overseas resources of these organisations and marginalise their impacts in local governance.

In recent years, with the passing of the Chinese Charity Law that relaxed registration and fundraising requirements for domestic NGOs, private philanthropic foundations have been on the rise (Simon and Snape 2018; Teets 2018). Many foundations have actively supported grassroots NGO development in Sichuan, especially in the areas of post-disaster recovery and community rebuilding. At the same time, as the Chinese government has acknowledged the legitimate role of NGOs in supplying social services, NGOs in Sichuan now have various channels to seek government contracts for public service provision. When I visited the quake-struck areas in 2017, I found that almost all local NGOs, including those previously supported by overseas funding, had turned to domestic funding sources such as purchase-of-service contracting by different government agencies and flexible grant schemes from domestic foundations. The NGO representatives I talked to generally viewed foundations as an alternative-often preferable-source of funding compared to the government, in light of their more efficient, flexible, and constructive 'investment' approach and business management style. However, they also understood that foundations scarcely deviated from the agenda of the state, as they relied on the permission and support of the authorities. While the new funding game provides relatively stable financial support to NGOs, it forces them into competitions where they must actively accommodate the preferences of the funders. Some adjustments 
might be constructive for the purpose of organisational development, but most of these changes actually distracted NGOs from their original mission.

\section{A New Dawn for Chinese Civil Society?}

For many, 2008 was a 'Year Zero' for Chinese civil society, as the relief and reconstruction process following the Wenchuan earthquake witnessed a significant surge in spontaneous grassroots action and organisations offering help to local communities in the disasteraffected areas (Roney 2011; Shieh and Deng 2011; Teets 2009; Zhang et al. 2013). Scholars closely following post-quake developments over the long term, however, are more hesitant in their assessment. For instance, Christian Sorace (2017) has illustrated the topdown nature of the reconstruction process, effectively showing how the tragedy was taken as a perfect opportunity for the Chinese leadership to demonstrate strength and leniency, but hardly created opportunities for a substantive expansion of civic participation. $\mathrm{Xu}$ Bin (2017) has observed the state's cruel response to complaints and claims of parents who lost their children in the earthquake, as well as the increasing marginalisation of civil society organisations. Carolyn Hsu (2017) has noted that although NGOs and social entrepreneurship are transforming China by mobilising popular resources and support to solve various social problems, the state, meanwhile, is taming their productive powers for its own ends. Thus, the game being played is very different from that which many observers predicted at that time, and the rise of Westernstyle civil society in China appears to be little more than a mirage.

My research echoes these recent critical works. The post-quake development trajectories of various local NGOs show that, although after the earthquake the Chinese government embraced the third-party management model and a more open associational environment, it remains unclear whether Chinese NGOs can flourish and contribute to the rise of a civil society in the western sense of the term. In fact, most of these NGOs have limited aspirations that do not extend to promoting civil society as a political space: they simply wish to avoid trouble and complement the state in serving populations in need. Moreover, the narrowing of funding sources has caused anxiety and driven NGOs to compete for the favour and patronage of donors. Recently established NGOs are likely to become government- or business-like organisations before they can demonstrate their unique value. Indeed, over the past nine years, I have witnessed NGO development in the quake zones transform from a grassroots-driven, relatively organic, and untamed process, first into a rather fluid and dynamic situation, and then into a topdown managerial set of procedures. Still, not everything is lost. The new funding game that sees the coexistence of government and business rationales, as well as recent developments like the facilitated channels for philanthropic public fundraising and NGOs' versatile strategies for self-sufficient growth, may open new windows of opportunity for Chinese NGOs. 